\title{
MODEL OF MANAGEMENT OF THE QUALITY OF THE GEOSPATIAL INFORMATION IN THE AEROPHOTOGRAMETRIC SERVICE OF THE AIR FORCE OF CHILE, BASED ON STANDARDS ISO TC/211
}

\author{
Joselyn Robledo Ceballos \\ Aerophotogrametric Service, Joselyn.robledo@saf.cl
}

\begin{abstract}
:
The following work proposes a model of quality assurance, specific for geospatial information, developed in the Aerophotogrametric Service of the Chilean Air Force, based on international standards such as ISO 9001 and TC/ 211 standards, statistical tools, technology and the tools that will allow manage, evaluate and make better use of geospatial information at the corporate, national or regional level for decision making. The following model, proposes a scheme for the implementation of an integrated Quality Management System, specific for geospatial information, based on international standards such as ISO 9001 and ISO TC/211. This management system is implemented within the life cycle of a cartographic product (planning, production, operation and publication). This document only includes the regulations used in the Aerial Photogrammetric Service of the Chilean Air Force, but the model can be adapted to any organization and include other standards. To implement the model, first, the standards will be classified according to the life cycle of a product, depending on how they relate to the production process in the planning stages or design of the product, in the production, control of quality, generation of metadata or in its publication as a web service.
\end{abstract}

Keywords: Quality control, ISO TC/211, SDI

\section{Introduction.}

The geospatial information is increasingly relevant in society, its use has had an exponential growth that has reached unsuspected levels for some years. This increase is associated with geolocation and its multiple means of access for the common citizen, the state, the defense and in general for decision-making in various areas. Given the above, the correct management of geospatial information is fundamental since it will allow it to be exploited safely as a support tool to make decisions about the territory.

In addition, Spatial Data Infrastructures (SDI) have been developed at different levels worldwide and their main objective is to share and dispose geospatial information for their use and collaboration with sustainable development at the country or regional level, this implies the possibility of make relevant decisions based on this geospatial information. This can be very attractive from the theoretical point of view, but there is a relevant element that few have been concerned with associated with the following questions: What is the quality of the geospatial information that is available in the SDI? How can I control it? How relevant is quality in the different levels of SDI? Is the information reliable? These questions are basic to understand the real importance of controlling quality, because if we do not know the quality of the data and its associated metadata, we cannot use and reuse the information correctly and reliably, which implies distancing us from the true meaning of an IDE, which is to share geospatial information to support decision-making and collaborate with the sustainable development of the countries.

Given the above, the "quality of the geospatial information" is a critical point, since it is the one that determines the usability of the data and allows these to be a real contribution to the decision making according to the territory, therefore, the measurement of this quality (qualitative and quantitative) and its report to all users, is essential if we really want to position geospatial information as technically and technologically exploitable, usable by all and a contribution to sustainable development.

Based on the information presented, geospatial information management should be a tool that considers the life cycle of a cartographic product, its quality control, traceability, standardization and interoperability. The following document proposes a specific assurance model for geospatial information of the Aerophotogrametric Service, based on international standards such as ISO 9001, TC/211 standards, statistical tools, technology and future perspectives that will allow better management, evaluation and use of the Geospatial information at the corporate, national or regional level. 


\section{Scope of application in the Aerophotogrametric Service (SAF)}

The Aerophotogrametric Service, dependent on the Chilean Air Force, is the agency responsible for the capture of images, coming from airborne platforms as satellite from the national territory. It concentrates its efforts on the generation of products and services linked to Remote Sensing, Aerofotogrametry and Aeronautical Cartography, in addition to maintaining a historical archive of images.

The SAF has different sensors that give rise to several production lines, so its management is complex (large volume of information, different repositories, different formats, etc.). Given this, methodologies and technologies are constantly sought to be more effective and efficient with customers, the Institution and the State.

In a vision of the future, the SAF has implemented the corporate SDI (2015-2018), a project that contemplates the implementation of a system of operational excellence based on standards (ISO TC / 211 and OGC) and associated technologies, oriented to the management, traceability and quality of geospatial information, metadata and services.

For this, the implementation of specific regulations for geospatial information is required, for this reason within the SDI-SAF project, the development of a geospatial information management and quality assurance system was considered, with the objective of having a model that regulate the design, traceability, quality control and publication of the product.

\section{Model.}

The following model (Figure 1), proposes a scheme for the implementation of a specific Integrated Quality Management System for geospatial information, based on international standards such as ISO 9001 and TC / 211. This management system is implemented according to the life cycle of a cartographic product (planning, production, operation and publication). This document only includes the regulations used in the Aerophotogrametric Service of the Chilean Air Force, but the model can be adapted to any organization and include other standards.

To implement the model, first, the standards will be classified according to the life cycle of a product (Figure 1), depending on how each of them collaborates with some stage of the Productive cycle; such collaboration may be in the planning or design of the product, in the production and quality control, in the generation of metadata or in its publication as a web service. Also, there are some other rules that have a greater relationship with the management of the system or as support standards to give vocabulary, formats, models, etc.

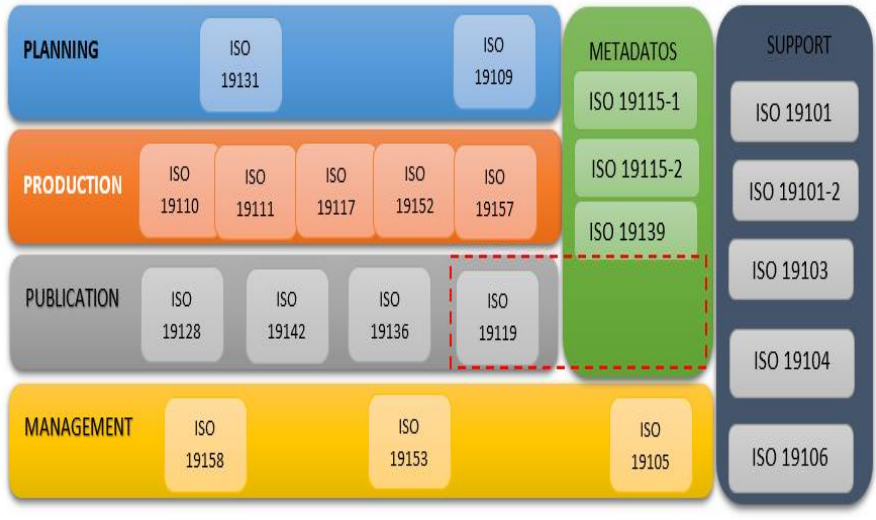

Figure $\mathrm{n}^{\circ} 1$ Classification of standards according to the life cycle of a product. Source: self-made

After classifying the standards, it is proposed to implement a model designed according to the life cycle and the specific characteristics of each product. In general terms, it begins with the stage associated with the design of the product, in which the objectives, the conceptual design and the technical specifications are determined (these will be the basis of productive management). Once the product is designed, the production stage begins with the main tasks of establishing and executing the production processes and controlling the quality of each stage, determining the level of compliance according to the technical specifications (of the design stage), Then, if the quality is accepted, the product must be cataloged by creating metadata.

Finally, and if the product design requires it, we proceed to publish through the services and / or web applications to organize the data in an interoperable way. In parallel, to guarantee the operation of the model, there must be a quality management system, in this case, based on regulations related to management such as ISO 9001 and ISO 19158, which will allow the system to be managed, controlled and improvements to be determined continuously and sustainable in the time they nourish the system. 


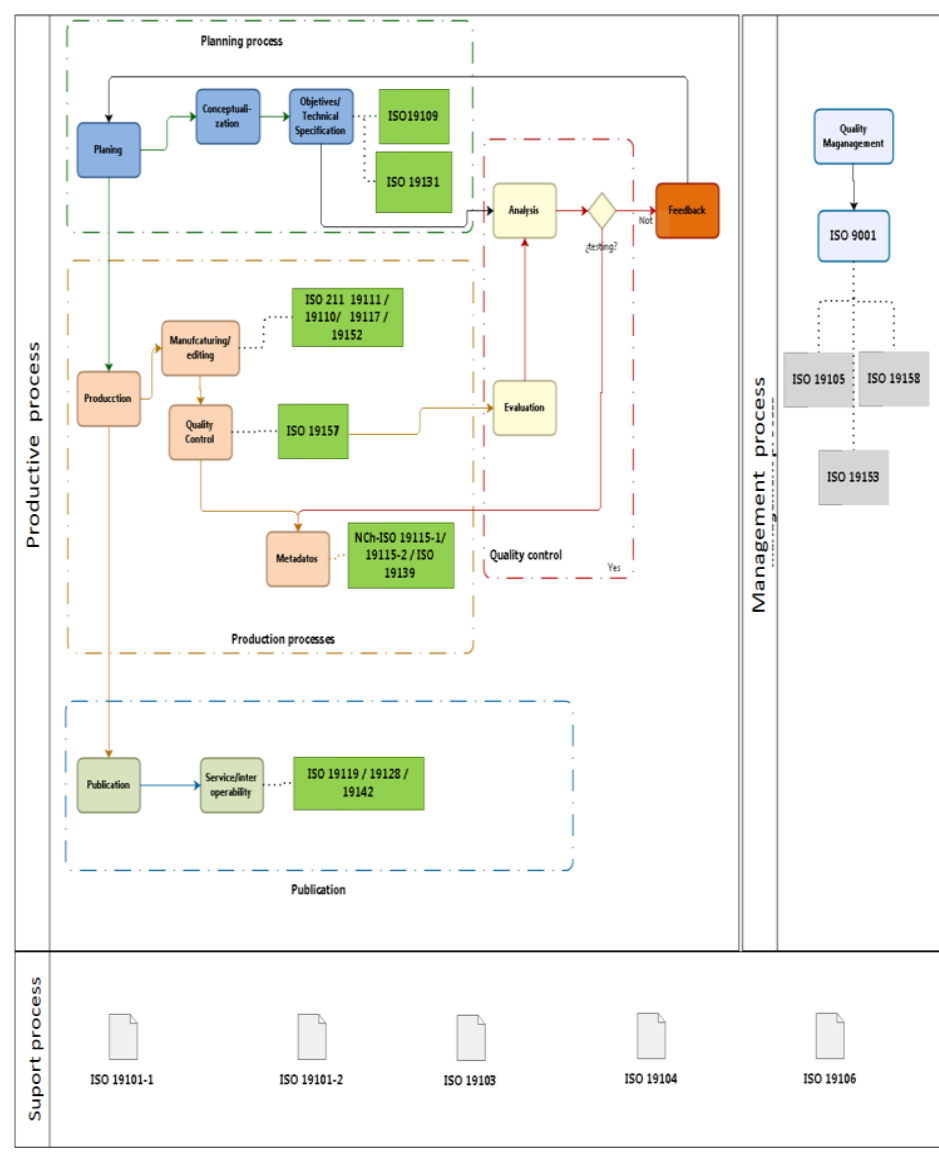

Figure $\mathrm{N}^{\circ} 2$ Geospatial Information Management and Quality Process. Source: self-made

\section{Proposal for quality control in all production lines.}

The process of quality evaluation according to ISO 19157 would be given by the different phases of the life cycle of a product.

- Development of specifications.

- Quality control during the creation of the data set.

- Inspection of conformity to a specification of the data set.

- Conformity assessment of a data set with user requirements.

- Quality control during the update of a data set.

The implementation of this integrated quality system considers simple work guidelines to: register the generation processes of each product, insert quality controls and report the results through metadata, in this way it will be delivered to the user's knowledge of the acquired product (National Institute of Normalization, 2014).

In practice, the following scheme is proposed:

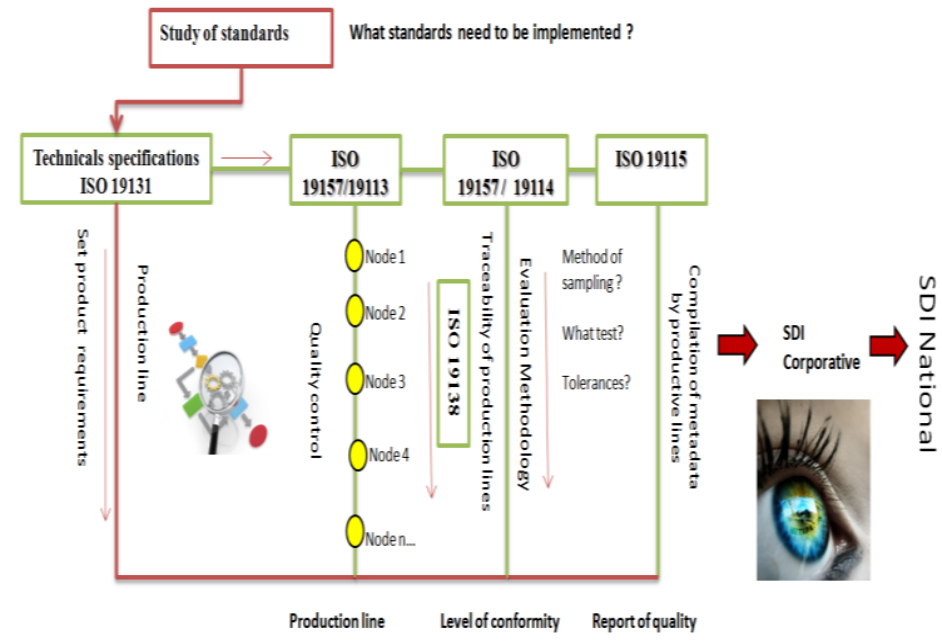

Quality management system ISO 9001/ISO 19158

Figure ${ }^{\circ} 3$ Quality control and management of geospatial information. Source: self-made.

Another fundamental aspect in this model is the quality control of the products, since it articulates the launch of each stage and is the basis of the Management System.

Quality in production processes is a fundamental aspect of the competitiveness of companies, traditionally quality has been linked to large multinationals, however, society and companies have been involved and quality is not just a business issue.

The Geomatics is still far from the habits of quality, but this paradigm must be a change and cartographic production must be understood in the same way as a productive industrial process.

The new paradigm of distribution and use of geospatial information is the spatial data infrastructure, and quality is a key factor to achieve interoperability and the real benefits of using different spatial data sets.

The quality control in the SDI must be carried out during the generation of the product, the level of complexity of these controls varies according to the cartographic product that is being produced. It is not the same control mapping generated with the existing information, that the generation of a mosaic or a digital map obtained from an aerial photogrammetric flight that involves its respective planning, flight control, process guide, restitution, field classification, etc. Performing these quality controls based on regulations and standards are fundamental to ensure certain statistical parameters of the product that finally give confidence levels to users depending on this quality.

As appropriate, Figure n $\left.\right|^{\circ} 4$ summarizes some quality controls associated with different types of cartographic products. 


\begin{tabular}{|c|c|c|}
\hline Process & Quality Control & Regulations \\
\hline Photogrammetric flight & $\begin{array}{l}\text { Flight Control } \\
\text { - Parámetros Control. } \\
\text { - Flown vis planned control. }\end{array}$ & Own metodologies. \\
\hline Image control. & $\begin{array}{l}\text { - Image quality control (shadows, scratches, atmospher- } \\
\text { ic effects etc.). } \\
\text { - Radiometric control. }\end{array}$ & Own metodologies. \\
\hline Topographic control. & - Adjustment result. & Standard metodologies.. \\
\hline $\begin{array}{l}\text { Point Cloud control, with } \\
\text { Lidar sensor. }\end{array}$ & $\begin{array}{l}\text { - Coverage. } \\
\text { - Number of points per square meter } \\
\text { - Vertical Positional Accuracy }\end{array}$ & $\begin{array}{l}\text { - Own metodologies. } \\
\text { - } \quad \text { ISO 19157/ISO } 19138 .\end{array}$ \\
\hline Mosaic & $\begin{array}{l}\text { - Coverage } \\
\text { - Matching } \\
\text { - Devices } \\
\text { - Horizontal Positional Accuracy. }\end{array}$ & $\begin{array}{l}\text { - OWn metodologies. } \\
\text { - } \quad \text { ISO 19157/ISO } 19138 .\end{array}$ \\
\hline Orientation & $\begin{array}{l}\text { - Quality control orientation through positional accuracy } \\
\text { test. } \\
\text { - Adjustment Statisitical Control }\end{array}$ & $\begin{array}{l}\text { - Own metodologies. } \\
\text { - SO 19157/ISO } 19138 .\end{array}$ \\
\hline Digital Map & $\begin{array}{l}\text { - Vertical and Horizontal Positional Accuracy. } \\
\text { - Completeness. } \\
\text { - Thematic Accuracy. }\end{array}$ & $\begin{array}{l}\text { - Own metodologies. } \\
\text { - SO 19157/ISO } 19138 .\end{array}$ \\
\hline $\begin{array}{l}\text { Satellite image Clasifica- } \\
\text { tion }\end{array}$ & - Thematic Acuracy, Satellite image Clasification. & $\begin{array}{l}\text { - Own metodologies. } \\
\text { SO 19157/ISO 19138. }\end{array}$ \\
\hline
\end{tabular}

As can be seen in Figure 1, the quality of the geospatial information is related to standards, such as ISO 19113, 19157, 19158, 19115, among others. These have to work together and be applied in the structure of production lines, quality control, traceability and metadata. This implementation should not be standard, but be well adapted to the production design of each company.

To implement these quality control systems, the following is proposed:

a) That the system is backed by basic management standards such as ISO 9001 and ISO 19158, which make quality control mandatory since the only certifiable standard is ISO 9001.

b) All the products to be generated must have technical specifications that are based on ISO 19131, which will determine the technical requirements for quality control.

c) Once the requirements have been established, the production lines should be studied and the quality control to be determined in each node, this control can be qualitative or quantitative, see examples in figure 4. The quantitative quality controls should be based on a statistical basis; You can use various sampling methods and tests designed specifically for this purpose, such as Positional Accuracy (ASPRS, NSSDA, EMAS, etc.)

d) Once quality control has been defined in a specific production node, its impact must be analyzed as positive (on product quality) or negative (costs associated with this). Based on these two variables, the cost of the benefit must be determined. This is not to dismiss quality control; this is to find the best way to carry out its implementation e) Then the theoretical quality must be calculated (it is derived from the technical specifications) and compared with the real quality (derived from the quality control) to finally determine if it complies with the technical specifications. This must be done in each production node to control the product and detect deviations in time to obtain a final product that meets the customer's requirements, avoiding or reducing the costs of No Quality.

f) Taking into account the results in each node, you must enter the software information corresponding to quality control, traceability and their respective metadata, this as you create the product and not at the end of production.

a) Finally, the quality and metadata will be known, the product and all its additional information may be uploaded to the Corporate SDI, which will exploit the benefits of the system, using intelligent searches (semantics) and services specially designed for the Service and external customers. as SDI Chile. With this methodology, the geospatial information within any institute or cartography company can be properly controlled and managed. In addition to optimizing processes and finally be more efficient and effective.

\section{Management of geospace information processes.}

The geospatial information management process is associated with multiple processes that are unified and harmonious in a single system that allows to determine, control, inform and improve the quality of a cartographic product or geospatial information. This methodology associates the life cycle of a product with the productive processes of: management, support and reprocessing for continuous improvement.

The management processes are fundamental for any System, since thanks to these the quality of the products can be assured, at least procedurally.

ISO 9001: 20015, states that: "The adoption of a quality management system is a strategic decision for the organization that can help it improve its overall performance and provide a solid foundation for sustainable development initiatives" (Instituto Nacional de Normalization, 2015).

Within the previous context, there is also ISO 19158: 2014 which, as indicated by the standard "provides a framework for the assurance of the specific quality of geospatial information" (National Institute for Standardization, 2014). It is based on the principles of quality and procedures for assessing the quality of geospatial information identified in ISO 19157 and the general principles of quality management defined in ISO 9000. 
Through the application of ISO 19158: 2014, as a tool for quality assurance, an organization can manage the production of geospatial information based on different requirements in terms of cost, quantity, quality and opportunity. In addition, it provides opportunities to improve understanding between customer requirements and the productive capacities of the producer.

An organization that implements ISO 19158: 2014 ensures that the generation of its geospatial information is implemented under quality assurance procedures and quality assessment in accordance with that standard. Quality assurance is a quality management activity focused on the confidence that quality requirements will be met (by a supplier). A quality evaluation procedure is a procedure by which a customer ensures that a supplier is able to deliver a product consistently with the required quality. Finally, to say that management in the production of geospatial information based on international regulations, is a tool that allows to guarantee the compliance of the procedures that are under these management systems, allowing to control the quality and traceability of the productive lines and to perform analysis based on continuous improvement.

\section{Conclusions}

In accordance with existing technology and market demands, geospatial information has become a fundamental pillar (support) in decision making for different issues related to geographic, economic and human activities, among others, contributing to the sustainable development of Nations For this reason, the implementation of specific rules for cartographic products has become a priority to begin with good practices in these areas and have reliable and quality information when making a decision, so that the result is a real contribution for the economic economy. and social welfare.

The implementation of these standards is not a simple task when there are no national implementation references (guidelines), since they are generic and require time for their study, in addition to the analysis of the critical points at each level of the product process, to then design a work methodology To ensure the correct practice of these standards, it is important to have as a basis a quality management system in accordance with the ISO 9001 standard, considering it more as an obligation than as a support for the management and correct practice of $\mathrm{TC} /$ 211 standards.

The generation of metadata is also important in this development, since it allows knowing the products themselves in detail and sharing this information with users, which benefits a better decision-making process. All this is part of one of the fundamental pillars for the creation of map navigators that have Intelligent Search Systems, information filters and interaction between geographic data, which is the basis for the creation of a spatial data infrastructure.

The Aerophotogrametric service of the Chilean Air Force, has incorporated these good practices in its procedures, delivering to its customers products of known quality, which will be interoperable, thus ensuring its usability.

\section{References}

Ariza López, F. J. (2002). Calidad en la produccion cartográfica. Jaén: RA-MA.

Ariza López, F. J. (2003). Fundamentos de evaluación de la calidad de la Información Geográfica. Jaén: Universidad de Jaén.

Delgado Fernández, T., \& Capote Fernández, J. L. (2009). Semantica espacial y descubrimiento de conocimiento para desarrollo sostenible. Proyecto CYTED-IDEDEDES 606AC294. La Habana: CUJAE.

Instituto Nacional de Normalización. (2012). NCh-ISO 19131:2012 - Especificación de productos de datos. Santiago.

Instituto Nacional de Normalización. (2014). NCh-ISO 19157:2014 - Calidad de datos. Santiago.

Instituto Nacional de Normalización. (2014). NCh-ISO 19158:2014 - Aseguramiento de la calidad del suministro de los datos. Santiago.

Instituto Nacional de Normalización. (2015). NCh-ISO 9001:2015 - Sistemas de gestión de la calidad - Requisitos. Santiago. 